\title{
Investigating the Standard Process of Conventional Gold Refining Process in Kelantan, Malaysia
}

\author{
Saadiah Kaspin ${ }^{1}$ and Nadiah Mohamad ${ }^{2}$ \\ ${ }^{1}$ Department of Contemporary Metal Design, Faculty of Art and Design, Universiti Teknologi MARA (UiTM), Shah Alam, \\ Selangor, Malaysia \\ ${ }^{2}$ Department of Fine Art, Faculty of Art and Design, Universiti Teknologi MARA (UiTM), Shah Alam, Selangor, Malaysia
}

\begin{abstract}
- the conventional method of gold refining process is widely used and it seems no further effort has been taken to improvise the system. Safety, productivity and reliability issue remains to be crucial barrier to local jewelers to refine their inhouse gold scrap. The findings have brought the researcher to conduct site visits to some of the refinery centers to identify their popularly known conventional gold refinery process. Based on researcher early observation during the site visits has founded that current refinery practice seems unsafe and dangerous due to improper handling of acidic chemical substances and unhealthy refining procedures at the workplace. The process normally produce smokes, poisonous fumes and smells that could endanger human's health, safety and pollutes the environment largely without proper control measures.
\end{abstract}

Keywords-component; gold; refining process; standard process; Malaysia

\section{INTRODUCTION}

According to Ministry Industry, Mineral and Geoscience Department in Kuala Lumpur, Malaysian, Malaysia is a gold producing country and its production on this mineral was about 4000MT yearly. [1]

In general, most of the small-scale gold mines are located in the States of Kelantan, Pahang, and Terengganu. In Malaysia, Kelantan is one of the most popular states amongst gold jewelry buyers due to its renown "Kelantan gold" via its unique traditional "design" concept offered at a very reasonable price, even sometimes lower than the industry gold prices. $[4,5]$

The price and its unique design has been an attraction to local tourism and jewelry industry that indirectly spur the development of the local economic development. In general substantiate by my early observation, Kelantan is the most renowned state for small/medium scale gold jewelry making as compared to others states in Malaysia like Terengganu and Pahang.

The case study opted Kota Bharu, Kelantan as due to the early one to one interview findings shows that most of the district based jewellers from Machang, Tanah Merah, Kuala Krai and Pasir Puteh sell their gold waste to gold refinery center located at Kota Bharu. The establishment of these gold refinery centers also has attracted established jewellers from other adjacent areas to get their service. This phenomenon has intrigued researchers' curiosity to acquire more crucial information about their gold processing devices and techniques used in local production particularly without advanced technology environment.

Although the effect of technological advancement has improvised global gold refining process, the researcher's findings stated that conventional method is still being used to refine gold in Kelantan.

\section{HISTORY OF GOLD RECOVERY PROCESS}

Recovery is the process of removing impurities from the precious metal. Gold going through refineries may either be recycled being purified and upgrade or on the final stage of its transformation from ore in the mine of bullion. [2]

Gold mining and recovery activities have set its footage since the golden ancient Egyptian time. J.H.F Notton, a well renowned researcher has produced a substantial evidence of information in his journal "Ancient Egyptian Gold Refining” published in Gold Bulletin dated 1st Mac 1974.

According to Notton; there was an evidenced on various activities relating to gold mining based on the large amount of gold used in rituals and religious activity. The findings also stated that the equipment used is technically good with high standard and precision.

The first recovery technique has been founded and introduced in the Ancient Egyptian era; about 500 B.C. It is based on the result of the chemical analysis that determines the ages and level of purity of the sample gold items founded during archeological activities. It was evidenced that the sample has higher gold purity as compared to normal gold alloy, which proved the usage of the gold refining techniques. [3]

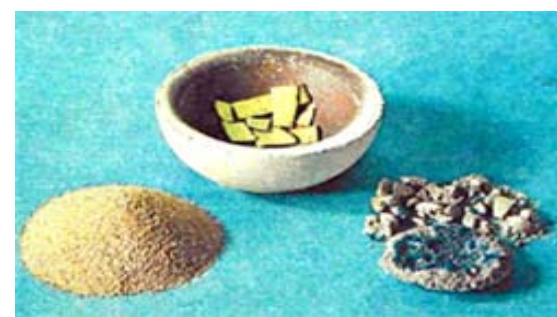

FIGURE I. SAMPLE OF THE EGYPTIAN GOLD RECOVERY EQUIPMENT. [3]

\section{Conventional Gold Recovery Process In Kelantan, MALAYSIA}

The locations for the case study on site observation are located at the local gold refiner premises at Kota Bharu, 
Kelantan. Each location shows the creativity by the refiners themselves in order to make the gold recovery process conveniently according to their suitability.

The refining process was observed to be conducted in a small covered room located at their home backyard. Improper funnel has been built as a smoke ventilator to release acid and toxic gas moves out from the room. There are two limited spaces to separate refining area and melting area. The refinery is equipped with basic amenities such as water pipes and pail. Nevertheless, the whole refinery area's condition was poor and need a lot of improvement. $[4,5,6]$

The equipment is not a well designated device for refining process and unsafe position of gas tank was noted at the melting area. Toxic smokes clouds the area badly during the process and forced the worker to wear gas mask all the times. The workplace was considered dangerous and messy and could cause fatal accident to the refiners if no further actions are taken to resolve the matter. Though the method has been proven to work effectively and has been used for generations, major improvement is needed to change the technique and the process.[6,7,8]

Current practice is considered as unsafe and not economical in the long run. Despite of these weaknesses, the refiners doesn't have any options due to their limited knowledge and skeptical mind about the latest technology. Generally, it could be categorized as an unsafe, unhealthy and unsystematic condition of refining process particularly because it's being done in a dark covered room and the improper handling procedures of hazardous chemical substance like nitric acid. [6, 7, 8]

Basically, there are 4 stages in gold refining as shown in figure II below:

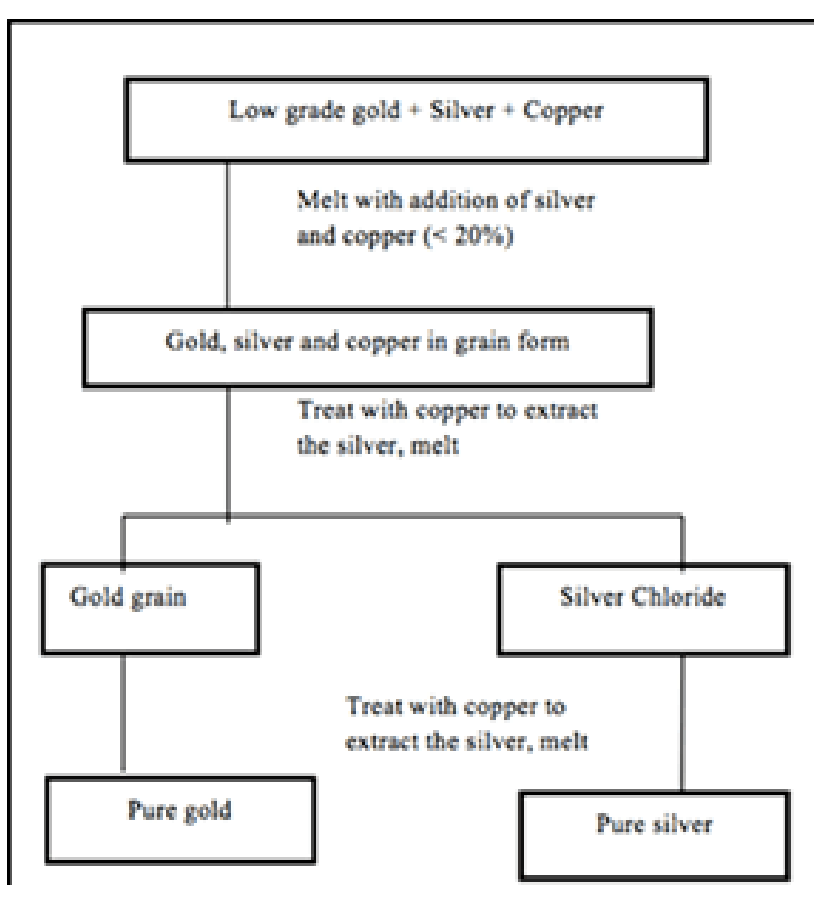

FIGURE II. OUTLINE OF CONVENTIONAL GOLD RECOVERY PROCESS.

\section{A. Stage 1}

The first stage in gold refining is to melt the gold. The jewellery from 916 carat gold and silver goes through the melting process. Before that, put the gold jewellery and silver in a crucible and the ratio for gold and silver is $1: 1$. Pour the gold and silver solid into metal pan. Then acid nitric is poured into the pan to crush the gold.

Then the nitric acid is re-poured from the pan into the dedicated pail. After that, the pan is heated until the gold solution dry. Subsequently, raise the gold from the pan for remelting process. The process only takes 5 minutes to complete. During the re-melting process, copper is used as a catalyst to turn the gold raw and allowed the mixed gold and silver return to its origin.

The usage of copper will affect the mixed gold and silver and change it into yellow pale or red. After the mixture is crushed and melted, pour it into the water. This process will takes 5 minutes to complete. [4, 5]

\section{B. Stage 2}

The second stage is a refining process. This stage is divided into three parts. Firstly, place the solid gold into the pan. Use one dipper of acid nitric until the gold sink. Before that, the acid must be free and clean from any materials. Put the pan on the kitchen and heat it. During the heating process, the copper will evaporate due to the hazardous dark brown acid fumes. If the fumes become slightly white, that signals that all copper metals have been fully evaporated.

Secondly, the water is poured into the pan to remove all the fumes. Slowly reduced the heat and raised the pan. There are golds in seeds form and some water left in the pan. The water automatically contains silver because when the heating process, silver has been transformed into liquid form and mixed with the acid nitric. The acidic water that contains silver will later be poured into the pail and leaves the gold in the pan. Pour some water in the pan to remove balance of acid nitric. Put some water and stir regularly.

Later, new acid nitric is poured into the pan and the gold is heated again. White color fumes will be produced during this second heating process in the absence of copper substance. Cooked until the acid boiled up. It will take longer time to boil due to the ductility and malleability factors possess by the gold solution. After the acid is boiled up, a lot of fumes will be produced. Acid that is used in this process can be kept and reused because it does not mix with silver and copper. The gold solution will later change its color into to red.

Subsequently, repeat all the disciplines as mention in the second part. After it's completed, the gold will change to the origin fine gold solution in red color. Dries it with slow fire to fasten the process. At this stage, the appearance of dried gold is in dust form. Dried spatula is used to get the gold. The whole refining process takes 45 minutes to complete.[4,5,6]

\section{Stage 3}

The third stage is to make the gold bullion. At first, the flux is used as catalyst to ease the gold melting process. The flux will later be placed at the bottom of ceramic crucible followed by gold dust spurred on top of the flux layer. Dried 
spatula is used to press the gold and flux together for the finishing purpose. The ceramic crucible will then be placed into the burning area for heating process. Start the burning process till the gold melted.

Borax is a type of chemical substance that is use to remove all the dirt during the melting process. The process will take half an hour to complete. The melted gold will then poured in the bullion mold. The bullion will be removed from the mold and water is used to reduce its temperature. This process takes 50 minutes in order to complete the whole cycle. The bullion will undergo through testing process to ensure its quality and purity. Standard gold purity level is $99.9 \%$. However, some of the refine gold only managed to produce only $98.0 \%$. [7, 8]

This reduction is mainly caused by the original contents of refined gold jewellery bought from the jewellers house or customers which are lower than the standard purity level. For example, marking initial or carat symbol of 916 gold means the gold carat contains $91.6 \%$ purity. But in this case, the purity of gold is just $90.0 \%$. They claimed some craftsmen's and jewellers house reduced the purity of gold to gain more profit. It is a fact that many customers were unable to identify the purity of the gold contents accurately due to its complicated technicalities. [6, 8]

\section{Stage 4}

Silver that has been changed into the liquid form turned into light green color because its mixtures with acid nitric. Pour some water to reduce fumes and temperature. Put in copper to extract silver metal from the mixture. It would takes 5- 6 hours to complete the process. Silver solution that attached to the copper is white in color and is very soft. Sufficient water quantity in mixture of acid and silver will avoid the copper from being eroded. Results from the above refining process shows that the traditional method that has been used was unsystematically done. Inaccurate calculation and improper instruments arrangement have affected the percentage of gold purity. $[4,5,6]$

\section{Cost Analysis For Gold Recovery PROCEss}

From the observation, the equipment and material used in conventional recovery process was made from steel or plastic and available at the market. Therefore, the actual cost of every equipment and material from each method used in traditional process were identified for its weakness and strength.[6,8]

TABLE I. COST ANALYSIS OF GOLD RECOVERY PROCESS.

\begin{tabular}{|c|c|c|}
\hline \multicolumn{3}{|c|}{ Conventional Gold Recovery Process } \\
\hline No & Equipment/ Material & Price ( RM) \\
\hline 1 & Nitric Acid & 80 \\
\hline 2 & Pan & 25 \\
\hline 3 & Kui & 1 \\
\hline 4 & Stainless Steel & 160 \\
\hline 5 & Torch Set & 25 \\
\hline 6 & Gas silinder & 15 \\
\hline 7 & Plastic Pail & RM 301 \\
\hline \multicolumn{2}{|c|}{} \\
\hline
\end{tabular}

According to the above table, the cost for conventional recovery process is RM 301.00. The expensive equipment in this process was a torch set that used in melting process.[7,8]

\section{Time Consuming To Complete The Conventional GOLD RECOVERY PROCESS}

The conventional method was conducted at night starting from 8.00 o'clock. Time duration for conventional gold recovery process for method A was about 1 hour and 5 minutes. It took a longer time only during when the gold was allowed to dissolve in acid niric and the process was repeated untill the brown fumes disappeared. In a same time, the funnel placed above the kitchen allowed the brown fumes to spread out to the air and speed up the recovery process. $[6,7,8]$

TABLE II. ANALYSIS ON QUANTITY OF GOLD RECOVERED BEFORE (PRE) AND AFTER (POST) REFINING PROCESS.

\begin{tabular}{|c|c|l|l|l|}
\hline $\begin{array}{c}\text { Traditional } \\
\text { method }\end{array}$ & $\begin{array}{l}\text { Purity } \\
\%\end{array}$ & $\begin{array}{c}\text { Weight Gold } \\
\text { Before Process }\end{array}$ & $\begin{array}{c}\text { Weight Gold } \\
\text { Recovered }\end{array}$ & Purity \% \\
\hline A & 83.5 & $25 g m$ & $24.3 g m$ & 99.0 \\
\hline
\end{tabular}

The amount of gold recovered through method A was 0.7 gram.

TABLE III. CHEMICAL COMPOSITION OF THE SOLID GOLD SAMPLES FROM CONVENTIONAL METHOD USING XRF ANALYSIS.

\begin{tabular}{|l|l|l|l|l|l|}
\hline Method & \multirow{2}{*}{ Sample } & \multirow{2}{*}{$\begin{array}{c}\text { Weight } \\
(\mathrm{gm})\end{array}$} & $\begin{array}{c}\text { Gold } \\
\text { as Au }\end{array}$ & $\begin{array}{c}\text { Silver } \\
\text { as Ag }\end{array}$ & $\begin{array}{c}\text { Copper as } \\
\mathrm{Cu}\end{array}$ \\
\hline $\mathrm{A}$ & & & 99.0 & 0.89 & 0.11 \\
& & 4.57 & & & \\
\hline
\end{tabular}

From the table above, it shows that chemical composition gold sample is $99 \%$ purity with appearance of $0.89 \%$ silver element and $0.11 \%$ copper.

TABLE IV. ANALYSIS ON GOLD THERMOGRAVIMETRIC ON CONVENTIONAL RECOVERY METHODS SAMPLES

\begin{tabular}{|c|c|c|l|c|}
\hline \multirow{2}{*}{ Method } & \multicolumn{4}{|c|}{ Sample was heated to $1200^{\circ} \mathrm{C}$ at $10^{\circ} \mathrm{C}$ min } \\
\cline { 2 - 5 } & Sample & Weight ( gm ) & Purity \% & Melting Point \\
\hline \multirow{2}{*}{ A } & ( ) & $4.57 \mathrm{gm}$ & 99.0 & $1090^{\circ} \mathrm{C}$ \\
\hline
\end{tabular}

According to the table above, the melting temperature of sample from method A was the highest with $1090 \mathrm{oC}$ due to its chemical compositions that consists a higher percentage of purity with $99 \%$ and it reflected from it resistant properties that can withstand high temperature untill 1090oC. The highest gold contained will contribute to the highest melting temperature of gold alloy.

\section{RESULTS AND FINDINGS}

The nitrogen dioxide produced from the conventional gold recovery process caused the air pollution and derived to the safety issues. This problem relates to the quality control of each methods used by the refiners. The finding also derives that this method was unable to filter out all silver and copper element and in a same time affect the quality of gold in terms of percentage. [6, 7,8$]$

From this research, the researcher hopes that it can be a starting point for other studies on gold recovery process. For example, the introduction of new small scale device or machine to refine gold from jewelry scrap. Other than that, the traditional recovery process through nitric acid and 
precipitation process must be improve to avoid the long period which was taken to complete the process and in the same time, it can avoid the gold losses from happening during filtering process.

The most important things are the benefit of refining inhouse in a small scale production must be weighed against the cost and yield of gold obtained from use of the gold refiners. In some cases, use of third party refiners may be more costeffective and easy to manage as compared to in-house refining process.

\section{ACKNOWLEDGMENT}

The authors are grateful for support from local refiners, Associate Prof. Dr. Zaini Hamzah from Faculty of Applied Science, University Technology MARA (UiTM) and Dr.Christopher W. Corti from World Gold Council (WGC). Last but not least, University Technology MARA (UiTM), Malaysia for their support in making this research successfully.

\section{REFERENCES}

[1] Mohamad Yusof Che Sulaiman and Azemi Hj. Eki ( 2004 ), Import and Export of Mineral, Mineral Malaysian Minerals Yearbook 2004, Department of Mineral and Geoscience, Kuala Lumpur.
[2] Kenneth Blackmore ( 1982 ) 'Buying Jewelry ( A Practical Guide)

[3] J.H.F Notton (1974 ) Egyptian Gold Recovery , Gold Buletin Magazine 1 Mac 1974, 7 (2), pg 50-56

[4] BINTIKASPIN, SAADIAH. "Improvement of traditional gold recovery process for jewellery scrap." PhD diss., Universiti Teknologi MARA, 2008

[5] Kaspin, Saadiah, Zuriati Mohamed Shaari, and Nadiah Mohamad. "An investigation on the effectiveness of traditional gold recovery process for jewellery scrap." (2009).

[6] Kaspin, Saadiah. "Small scale gold refining: Strengths and weaknesses." In Technology, Informatics, Management, Engineering, and Environment (TIME-E), 2013 International Conference on, pp. 32-36. IEEE, 2013.

[7] Kaspin, S., and N. Mohamad. "Gold refining process and its impact on the environment." In Environmental Engineering and Computer Application: Proceedings of the 2014 International Conference on Environmental Engineering and Computer Application (ICEECA 2014), Hong Kong, 25-26 December 2014, p. 19. CRC Press, 2015.

[8] Kaspin, Saadiah. "Eco gold: An improvement of traditional gold recovery process for jewellery scrap." In Business Engineering and Industrial Applications Colloquium (BEIAC), 2013 IEEE, pp. 784-788. IEEE, 2013. 